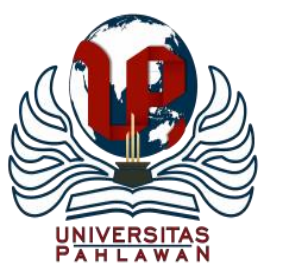

Jurnal Abdidas Volume 1 Nomor 2 Tahun 2020 Halaman 33- 37

JURNAL ABDIDAS

Community Development Service on Educational and Health Sciences http://abdidas.org/index.php/abdidas

\title{
PELATIHAN MEDIA VISUAL NON PROYEKSI BERBASIS KOMPUTER KARAKTERISTIK IPS DI SEKOLAH DASAR
}

\author{
Sunaryo $^{1}$, Saktian Dwihartantri ${ }^{2}$, Sunardin $^{3}$ \\ Universitas Muhammadiyah Tangerang, Banten, Indonesia ${ }^{1,2,3}$ \\ e-mail: sunaryonurachman@gmail.com ${ }^{1}$, saktiandwihartantri@gmail.com ${ }^{2}{ }^{2}$, sunardin1 @ yahoo.co.id ${ }^{3_{3}}$
}

\begin{abstract}
Abstrak
Pelatihan ini bertujuan untuk memberi motivasi kepada guru-guru sesuai dengan permohonan kepala sekolah dalam suratnya kepada Lembaga Penelitian dan Pengembangan pada Masyarakat (LP3M) Universitas Muhammadiyah Tangerang. Pelatihan Pembuatan Media Visual Non Proyeksi Berbasis Komputer Karakteristik Ilmu Pengetahuan Sosial dilaksanakan di SDN Kutabaru 1 Pasarkemis Kabupaten Tangerang. Adapun pesertanya terdiri dari bapak-bapak dan ibu-ibu guru dari SDN Kutabaru 1. Pada pelaksanaan pelatihan guru-guru selain mendapatkan materi pelatihan diberikan juga praktek membuat media poster dan media Bagan/ chart dengan bantuan komputer. Selain itu peserta juga mempresentasikan hasil karyanya. Dari hasil Pelatihan Pembuatan Media Visual Non Proyeksi Karakteristik Ilmu Pengetahuan Sosial tersebut dapat disimpulkan bahwa semua peserta dapat membuat media poster atau media bagan/ chart dengan baik.
\end{abstract}

Kata Kunci: Media Visual Non Proyeksi, Berbasis Komputer, Karakteristik Ilmu Pengetahuan Sosial.

\begin{abstract}
This training aims to motivate teachers in accordance with the request of the school principal in his letter to the Institute for Research and Development in the Community (LP3M), Muhammadiyah University, Tangerang. Training on Making Computer-Based Non-Projected Visual Media Characteristics of Social Sciences was held at SDN Kutabaru 1 Pasarkemis, Tangerang Regency. As for the participants consisting of fathers and teachers from SDN Kutabaru 1. In the implementation of the training the teachers besides receiving training materials were also given the practice of making poster media and chart / chart media with computer assistance. In addition, participants also presented their work. From the results of the Training on Making Non-Projected Visual Media Characteristics of Social Sciences it can be concluded that all participants can make poster media or chart / chart media well.
\end{abstract}

Keywords: Non-Projected Visual Media, Computer Based, Characteristics of Social Sciences.

Copyright (c) 2020 Sunaryo, Saktian Dwihartantri, Sunardin

$\triangle$ Corresponding author :

Address : Jl. Tanjung Gedong No. 13 Jakarta 11440

Email : sunaryonurachman@ gmail.com

Phone : 081219751400

DOI: https://doi.org/10.31004/abdidas.v1i2.10

ISSN 2721-9224 (Media Cetak)

ISSN 2721 - 9216 (Media Online) 
34 Pelatihan Media Visual Non Proyeksi Berbasis Komputer Karakteristik IPS di Sekolah Dasar - Sunaryo, Saktian Dwihartantri, Sunardin

DOI: https://doi.org/10.31004/abdidas.v1i2.10

\section{PENDAHULUAN}

Setiap guru sangat menginginkan siswanya lebih baik dan lebih berhasil dari mereka. Sebaliknya tidak ada guru di muka bumi ini yang menginginkan anak didiknya lebih rendah kedudukan sosialnya, gagal dalam hidupnya dan tidak memiliki masa depan yang cerah. Oleh karena itu, guru wajib membimbing dan memberi pendidikan yang terbaik. Pemahaman dan metode yang baik yang dimiliki oleh guru dalam memberikan motivasi akan memberikan hasil yang maksimal kepada siswanya, sebaliknya jika menggunakan metode yang salah kepada siswanya akan melahirkan generasi yang kerdil dan menjadi anak yang inferior.

Memiliki pendidikan yang baik dan prestasi yang gemilang kepada anak-anak, sebagai bukti cinta kita kepada putra-putri kita sebagai putra bangsa yang nantinya mampu mempersiapkan segalanya dengan baik. Namun tidak sedikit murid-murid merasa kesulitan dalam menerima pelajaran. Banyak guru-guru atau calon guru telah mengetahui atau mengakui manfaat dan bantuan media pelajaran terhadap proses pembelajaran agar lebih efektif dan efisien.

Agar pembelajaran berjalan lebih efektif dan efisien perlu adanya alat bantu pembelajaran yang sesuai di lingkungan sekolah. Untuk menguasai alat bantu pembelajaran para guru perlu dibekali cara membuat dan mengoperasikannya. Alat bantu pembelajaran tersebut dinamakan media pembelajaran. Menurut (Arsyad, 2013, hal.

3) kata media berasal dari bahasa Latin medius yang secara harfiah berarti tengah, perantara atau pengantar apabila dipahami secara garis besar media adalah manusia, materi, atau kejadian yang membangun kondisi yang membuat siswa mampu memperoleh pengetahuan, keterampilan atau sikap. Menurut (Daryanto, 2011 , hal. 4) dikatakan bahwa media pembelajaran merupakan sarana perantara dalam proses pembelajaran. Termasuk dalam media adalah: film, televisi, media cetak (printed material), komputer, instruktur dan lain sebagainya. Pengertian media menurut (Sanaky, 2009 , hal. 4) Media pembelajaran adalah sebuah alat yang berfungsi dan digunakan untuk menyampaikan pesan pembelajaran. Menurut (Sunaryo, 2017, hal. 4) (Sunaryo, Media Pembelajaran, 2017) Pengertian Media Pembelajaran adalah alat saluran komunikasi. Kata media berasal dari bahasa Latin, merupakan bentuk jamak dari kata medium. Secara harfiah kata media berarti perantara antara sumber pesan (a source) dan penerima pesan (a receiver). Sedangkan menurut (Istiningsih, 2012, hal. 15) Peralatan komputer dan fasilitas internet (bagian dari fasilitas TIK) yang diadakan sekolah atau yang diterima sekolah telah dirancang sedemikian rupa sehingga potensinya menunjang kegiatan pembelajaran yang pada akhirnya akan meningkatkan prestasi hasil belajar siswa. Menurut (Wilujeng, 2011, hal. 4) Kehadiran TI dalam pendidikan bisa dimaknai dalam tiga paradigma, yaitu: 1) TI sebagai alat atau berupa produk teknologi yang bisa digunakan dalam pendidikan, 2) TI sebagai bagian dari materi yang bisa dijadikan isi dalam pendidikan, dan 3) TIK sebagai program aplikasi atau alat bantu untuk manajemen pendidikan yang efektif dan efisien. Ketiga hal tersebut dihubungkan dalam sumberdaya TI yang secara khusus diposisikan dan diarahkan untuk mencapai visi dan misi pendidikan di Indonesia. Menurut (Budhi Oktavia dkk., 2011, hal. 6) Komputer telah mengambil cukup banyak proporsi sebagai alat pendidikan yang mampu memberikan kemudahan dan kesempurnaan suatu proses pendidikan. Komputer (internet) juga menjadi sumber informasi dalam 
35 Pelatihan Media Visual Non Proyeksi Berbasis Komputer Karakteristik IPS di Sekolah Dasar-Sunaryo, Saktian Dwihartantri, Sunardin

DOI: https://doi.org/10.31004/abdidas.v1i2.10

kehidupan modern. Berdasarkan beberapa pengertian dan pendapat para akhli di atas dapat disimpulkan bahwa media yang berbasis komputer dapat meningkatkan prestasi belajar siswa.

Untuk membuat dan memanfaatkan media menurut (Sunaryo, dkk., 2018, hal. 11) Media pembelajaran dapat diklasifikasikan menjadi dua yaitu : media yang memanfaatkan yang sudah ada dan media yang melalui proses desain (media by utilization dan media by design). Media by utilization terdiri dari: a) Benda sebenarnya, b) Memanfaatkan lingkungan, c) Narasumber, d) Fenomena alam. Media by design adalah: a) Modul, b) Program Audio, Visual, Video, c) Multi Media.

Menurut (Sunaryo, dkk., 2019, hal. 2) Ilmu Pengetahuan Sosial adalah suatu bahan kajian yang terpadu yang merupakan penyederhanaan, adaptasi, seleksi dan modifikasi yang diorganisasikan dari konsep-konsep dan keterampilan-keterampilan sejarah, geografi, sosiologi, antropologi, dan ekonomi, Geografi, sejarah, dan antropologi merupakan disiplin ilmu yang memiliki keterpaduan yang tinggi. Pembelajaran geografi memberikan wawasan berkenaan dengan peristiwa dan wilayah. Sejarah memberikan kebulatan wawasan berkenaan dengan peristiwa-peristiwa dari berbagai periode. Antropologi meliputi studi-studi komparatif yang berkaitan dengan nilai-nilai kepercayaan, struktur sosial, aktivitas-aktivitas ekonomi, organisasi politik, ekspresi spiritual, teknologi, dan benda budaya terpilih. Ilmu ekonomi tergolong dalam ilmu-ilmu tentang kebijakan pada aktivitasaktivitas yang berkenaan dengan pembuatan keputusan. Sosiologi merupakan ilmu-ilmu tentang perilaku seperti konsep peran kelompok, institusi, proses interaksi dan kontrol sosial.
Dari uraian di atas agar pembelajaran berjalan secara efektif dan efisien perlu dilaksanakan program pelatihan Program ini tidak hanya meliputi teori, melainkan juga praktik merancang dan membuat media diberikan secara komprehensif, sehingga peserta dapat memperdalam secara mandiri bidang penerapan yang diinginkan. Kekuatan utama pelatihan ini adalah dalam pembentukan kemampuan peserta dalam memperdalam teknik pembuatan media non proyeksi dalam rangka pemecahan masalah yang lebih menarik. Harapan dengan pelaksanaan pelatihan guru-guru secara komprehensif dapat menjadi guru yang menarik dan dapat mentransformasikan ilmu pengetahuan sehingga siswa dapat memahami pelajaran dengan mudah, akhirnya menjadi pelajaran yang menyenangkan. Tujuan akhir dari pelatihan ini adalah agar guruguru SDN Kutabaru 1, Pasar Kemis Kabupaten Tangerang dapat membuat Media Visual Non Proyeksi berbasis Komputer Karakteristik Pembelajaran IPS di SD. (Ilmu Pengetahuan Sosial di Sekolah Dasar) dengan baik.

\section{METODE}

Metode yang digunakan di dalam Pengabdian Kepada Masyarakat di SDN KutaBaru 1, Pasar Kemis Kabupaten Tangerang adalah melalui Pelatihan Media Visual Berbasis Komputer Karakteristik Ilmu Pengetahuan Sosial. Pemilihan media visual karena media visual dapat digunakan tanpa menggunakan arus listrik mengingat kondisi saat ini seringnya mati lampu dengan keadaan kondisi yang kurang stabil maka penggunaan media visual sangat tepat. Pelatihan ini bukan hanya teori tetapi dilakukan juga praktik pembuatan media visual berbasis komputer. Pemateri terdiri dari: 1) Saktian Dwi Hartantri, M.Pd., 2) Drs. Sunaryo, M.Ds. 3) Sunardin, M.Pd. 
36 Pelatihan Media Visual Non Proyeksi Berbasis Komputer Karakteristik IPS di Sekolah Dasar - Sunaryo, Saktian Dwihartantri, Sunardin

DOI: https://doi.org/10.31004/abdidas.v1i2.10

Waktu pelatihan dilaksanakan pada: Hari / Tanggal: Sabtu, 9 Februari 2019 , Tempat: SDN Kutabaru 1, Waktu: 08.00 sd. 12.00. Pesertanya adalah Guru-guru dari SDN Kutabaru 1. Sedangkan Instrumen yang digunakan untuk merancang dan membuat media adalah: RPP (Rencana Pelaksanaan Pembelajaran).

\section{HASIL DAN PEMBAHASAN}

Hasil dari Pelatihan Pembuatan Media Visual Berbasis Komputer adalah Pembuatan Media Visual Non Proyeksi berupa Poster Pembelajaran dan Chart/Bagan. Menurut Sunaryo (2017, Hal. 8-9) Media Poster selain berfungsi sebagai mediauntuk menyampaikan pesan dapat juga digunakan untuk mempromosikan suatu produk atau untuk menyampaikan pesan dari lembaga pemerintah atau lembaga lainnya. Bagan/Chart merupakan media grafis termasuk media visual yang tidak diproyeksikan. Fungsi bagan/chart adalah untuk penyampaian pesan berupa materi pelajaran agar lebih jelas jika dibandingkan dengan penyajian secara verbal atau tertulis saja. Pesan yang akan disampaikan melalui bagan/chart biasanya berupa ringkasan visual suatu proses, perkembangan atau hubungan-hubungan penting. Bagan/chart banyak jenisnya antara lain; bagan organisasi (struktur), bagan dalam bentuk gambar, bagan transparan, bagan petunjuk, bagan waktu, bagan pertumbuhan, bagan skema dan bagan lembar balik atau flip chart.
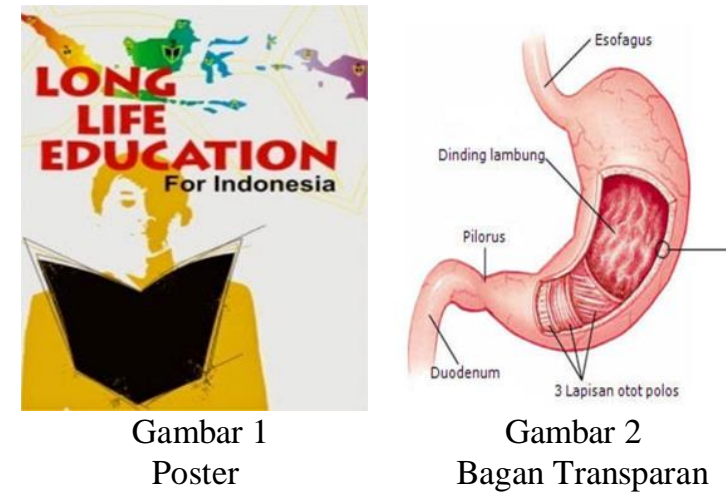

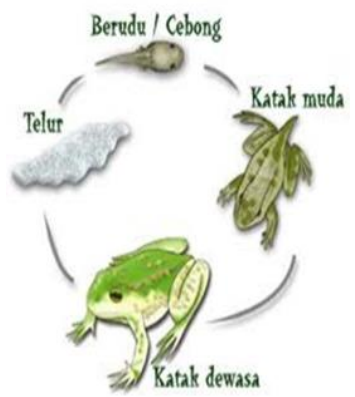

Gambar 3

Bagan Skema

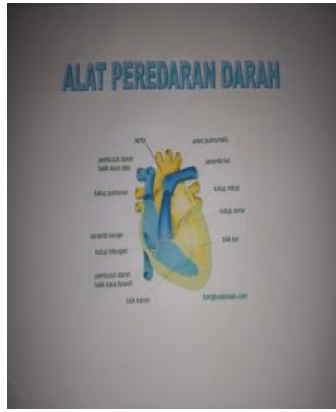

Gambar 5

Hasil Pelatihan

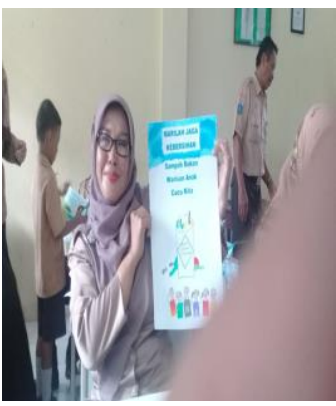

Gambar 4

Hasil Pelatihan

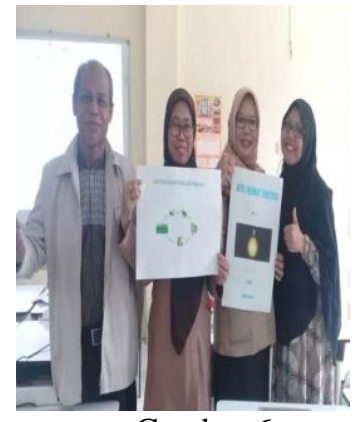

Gambar 6

Hasil Pelatihan

Hasil pelatihan dari peserta (Guruguru) SDN Kutabaru 1 adalah berupa posterposter pembelajaran dan Bagan-bagan/ Chart-chart Transparan dan Skema yang dapat digunakan sebagai Media Pembelajaran Visual Non Proyeksi Berbasis Komputer. Media ini sangat efektif dan efisien. Dapat digunakan walaupun dalam keadaan listrik padam. Karena media ini tidak memerlukan arus listrik.

\section{UCAPAN TERIMA KASIH}

Kami mengucapkan banyak-banyak terimakasih kepada:

1. Dr.Imam Muttaqin, MM. Selalu Ketua Lembaga Penelitian Pengembangan dan Pengabdian Kepada Masyarakat (LP3M) Universitas Muhammadiyah Tangerang. Yang telah memberi tugas kepada kami dalam rangka Pengabdian Kepada Masyarakat di SDN Kutabaru 1 Pasarkemis Kabupaten Tangerang. 
37 Pelatihan Media Visual Non Proyeksi Berbasis Komputer Karakteristik IPS di Sekolah Dasar - Sunaryo, Saktian Dwihartantri, Sunardin

DOI: https://doi.org/10.31004/abdidas.v1i2.10

2. H. Muhidin, M.Pd. selaku Kepala Sekolah SDN Kutabaru 1, Pasar Kemis, Kabupaten Tangerang yang telah memberi tempat pelatihan dalam rangka memotivasi guru-guru di SDN Kutabaru 1.

3. Dr. Enawar, S.Pd, M.M, MOS., Selaku Dekan Fakultas Keguruan dan Ilmu Pendidikan Universitas Muhammadiyah Tangerang.

4. Dr. Ina Magdalena, M.Pd Selaku Ketua Program Studi PGSD Fakultas Keguruan dan Ilmu Pendidikan Universitas Muhammadiyah Tangerang.

\section{SIMPULAN}

Dari hasil Pelatihan Media Visual Non Proyeksi Berbasis Komputer Karakteristik IPS di SDN Kutabaru 1 Pasar Kemis Kabupaten Tangerang Guru-guru peserta pelatihan selain diberikan materi ajar mengenai pembuatan Media Poster dan Media Bagan/ Chart dengan menggunakan Komputer. Peserta juga diberikan praktik pembuatan media tersebut dan hasilnya di presentasikan di depan kelas. Dari hasil praktik bapak-bapak dan ibu-ibu guru SDN Kutabaru 1 disimpulkan bahwa sesuai dari tujuan akhir dari pelatihan ini adalah agar guru-guru SDN Kutabaru 1, Pasar Kemis Kabupaten Tangerang dapat membuat Media Visual Non Proyeksi berbasis Komputer Karakteristik Pembelajaran Ilmu Pengetahuan Sosial di Sekolah Dasar (IPS) di Sekolah Dasar dengan baik. Dan hasilnya dapat disimpan agar bisa dijadikan media pembelajaran di Sekolah tersebut.

\section{DAFTAR PUSTAKA}

Arsyad, A. (2013). Media Pembelajaran. Jakarta: PT. Raja Grafindo Persada Jakarta.

Budhi Oktavia dkk. (2011). Laporan Pengabdian Kepada Masyarakat, Pelatihan IT Dalam
Pembuatan Media Pembelajaran Untuk Guru SMA se-Kota Padang. Padang: Jurusan Kimia FMIPA Universitas Negeri Padang.

Daryanto. (2011 ). Media Pendidikan. Bandung: PT. Sarana Tutoria Nurani Sejahtera.

Istiningsih. (2012). Pemanfaatan TIK Dalam Pembelajaran. Yogyakarta: PT. Skripta Media Creative.

Sanaky, H. A. (2009 ). Media Pembelajaran. Yogyakarta: Safiria Insani Press.

Sunaryo. (2017). Media Pembelajaran. Jakarta: Pendidikan Guru Sekolah Dasar FKIP Universitas Muhammadiyah Tangerang.

Sunaryo, dkk. (2018). Laporan Pengabdian Kepada Masyarakat, Pelatihan Media Non Proyeksi Berbasis Komputer di SDN Gempolsari Sepatan Timur Kabupaten Tangerang. Tangeran: Prodi Pendidikan Guru Sekolah Dasar FKIP Universitas Muhammadiyah Tangerang.

Sunaryo, dkk. (2019). Laporan Pengabdian Kepada Masyarakat Mandiri, Pelatihan Media Visual Berbasis Komputer dengan Karakteristik Ilmu Pengetahuan Sosial di SDN Kutabaru 1 Pasar Kemis Tangerang. Tangerang: Lembaga Penelitian Pengembangan dan Pengabdian Kepada Masyarakat

Susanto, A. (2013). Teori Belajar dan Pembelajaran di Sekolah Dasar. Jakarta: Prenada Media Group.

Wilujeng, H. (2011). Laporan Pengabdian Masyarakat, PELATIHAN PEMBELAJARAN MATEMATIKA BERBASIS TI GURU SD KOTA TANGERANG . Tangerang: Prodi Pendidikan Matematika FKIP Universitas Muhammadiyah Tangerang. 